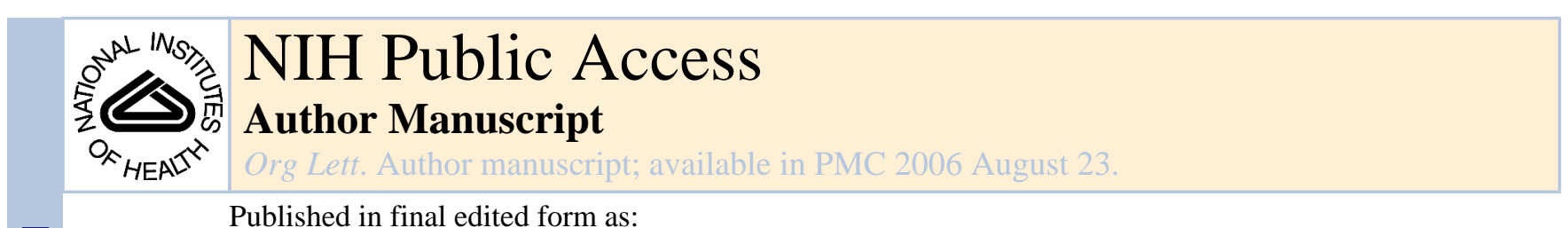

Published in final edited form as:

Org Lett. 2005 October 13; 7(21): 4585-4588.

\title{
Synthesis of Diethynyltriptycene-Linked Dipyridyl Ligands
}

\author{
Jeremy J. Kodanko, Anna J. Morys, and Stephen J. Lippard ${ }^{\star}$ \\ Department of Chemistry, Massachusetts Institute of Technology, Cambridge, Massachusetts \\ 02139
}

Abstract

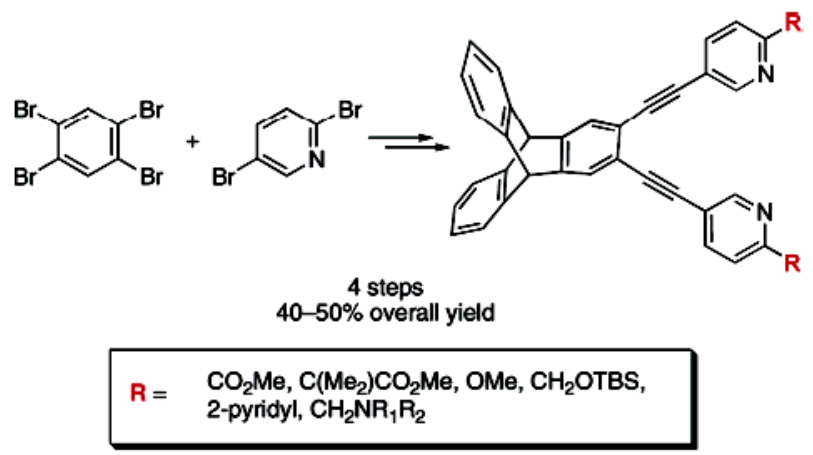

An efficient route to a new family of dinucleating ligands has been developed. A convergent strategy to these ligands involved dual Sonogashira cross-coupling of 2,3-diethynyltriptycene with a variety of functionally diverse 5-bromopyridines. The resultant ligands were accessed in four steps and 40$50 \%$ overall yield from 1,2,4,5-tetrabromobenzene. Synthesis of an imidazole and a quinoline derivative by this method is also described.

Enzymes that utilize diiron active sites catalyze a variety of key functions in Nature. These include the selective hydroxylation of methane to methanol (MMOH), ${ }^{1}$ conversion of deoxyribonucleotides to ribonucleotides (RNR-R2), ${ }^{2}$ and dehydrogenation of fatty acid side chains $(\Delta 9 \mathrm{D}) .{ }^{3}$ The active sites of this family of enymes have several common structural features, including a carboxylate-rich coordination environment and syn histidine $\mathrm{N}$-donor substituents. To illustrate, the diiron(II) active site of reduced MMOH is shown in Figure 1.

Much progress has been made over the last two decades in creating synthetic ligands to model the active sites of these diiron enzymes, although many challenges remain. ${ }^{4}$ One goal that has not been realized is to prepare the diiron(IV) oxo intermediate of $\mathrm{MMOH}$ in a synthetic complex..$^{5}$ This achievement would be valuable because this high-valent intermediate can insert an oxygen atom into the strong $\mathrm{C}-\mathrm{H}$ bond $(104 \mathrm{kcal} / \mathrm{mol})$ of methane. DFT calculations have suggested that enforcing a syn coordination geometry of the N-donors with respect to the $\mathrm{Fe}-\mathrm{Fe}$ vector could have an important stereoelectronic consequence in reproducing the hydrocarbon oxidation activity of $\mathrm{MMOH}^{6}$

Recently, a ligand capable of inducing syn coordination of two N-donors was described. ${ }^{7}$ This molecule, termed $\mathrm{Et}_{2}$-BCQEB (Figure 2), was used to synthesize the diiron compound $\left.\left[\mathrm{Fe}_{2}\left(\mathrm{Et}_{2} \mathrm{BCQEB}\right)\left(\mu-\mathrm{O}_{2} \mathrm{CAr}^{\mathrm{Tol}}\right)_{3}\right](\mathrm{OTf})\right]$, where ${ }^{-} \mathrm{O}_{2} \mathrm{CAr}^{\mathrm{Tol}}$ is 2,6-di(p-tolyl)benzoate.

lippard@mit.edu.

Supporting Information Available: Experimental procedures for preparation of for $\mathbf{2}, \mathbf{4 e}-\mathbf{g}$, and $\mathbf{5 a}-\mathbf{i}$ including characterization data. This material is available free of charge via the Internet at http://pubs.acs.org. 
Although $\mathrm{Et}_{2} \mathrm{BCQEB}$ produced a syn $\mathrm{N}$-donor complex, the ligand was not readily available. The synthesis involved seven steps and furnished $\mathrm{Et}_{2} \mathrm{BCQEB}$ in only $2 \%$ overall yield from anthranilic acid. Therefore, efforts were made to develop a more efficient route to a second generation of syn $\mathrm{N}$-donor ligands to facilitate further studies in this area.

To expedite the synthesis of the syn N-donor ligands, a more convergent strategy was sought. The new plan incorporates a late-stage coupling between the heteroaryl N-donors and a diethynylarene. ${ }^{8}$ The linker 2,3-diethynyltriptycene 2 (Scheme 1 ) was chosen as a modification of the original diethynylbenzene scaffold of $\mathrm{Et}_{2} \mathrm{BCQEB}$, in anticipation that the extra aromatic rings would enhance the crystallinity of its metal complexes. Dual Sonigashira coupling of 2,3-dibromotriptycene (1) ${ }^{9}$ and 2.5 equiv of trimethylsilylacetylene using a catalyst combination of $2 \mathrm{~mol} \% \mathrm{Pd}\left(\mathrm{PPh}_{3}\right)_{4}$ and $2 \mathrm{~mol} \% \mathrm{CuI}$ in piperidine at $100{ }^{\circ} \mathrm{C}$ furnished the coupled product, which was desilylated with $\mathrm{K}_{2} \mathrm{CO}_{3}$ in $\mathrm{MeOH}$, giving 2 in $81 \%$ yield over two steps.

To provide greater access to a variety of heteroaryl coupling partners, the syn N-donor substituents were changed from quinoline to pyridine. Several bromopyridines (4a-d) that could serve as components in ligands similar to $\mathrm{Et}_{2}-\mathrm{BCQEB}$ were readily available from 2,5dibromopyridine 3 (Scheme 2), ${ }^{10}$ a versatile and commercially available starting material that can be selectively functionalized in either the two or the five position. ${ }^{11}$

To add to the collection of available coupling partners, routes to three other 5-bromopyridines were developed (Scheme 2). Reaction between the lithium enolate of methyl isobutyrate and 3 proceeded smoothly, ${ }^{12}$ providing the pyridine acetic acid derivative $4 \mathbf{e}$ in one step and $94 \%$ yield from $3 .{ }^{13}$ Reductive aminations between 2 -formyl-5-bromopyridine $(\mathbf{4}, \mathrm{R}=\mathrm{CHO})^{10 \mathrm{c}}$ and two aminomethyl pyridine derivatives ${ }^{14}$ were mediated by thionyl chloride and $\mathrm{NaBH}_{3}$ $\mathrm{CN}$ in $\mathrm{MeOH}$, which afforded $\mathbf{4 f}$ and $\mathbf{4 g}$ in 61 and 63\% yield, respectively.

Next, Sonogashira coupling reactions between 2,3-diethynyltriptycene (2) and the bromopyridines 4a-g were investigated (entries 1-7, Table 1). Optimal conditions for coupling of 2 with 4a-g incorporated 2.1-2.5 equiv of the 5-bromopyridine, $10 \mathrm{~mol} \%$ of $\mathrm{Pd}_{(}\left(\mathrm{PPh}_{3}\right)_{4}$ as the catalyst, and a combination of $\mathrm{Et}_{3} \mathrm{~N}$ and $\mathrm{THF}$ at $55^{\circ} \mathrm{C}$. A number of functional moieties that ligate metal ions were tolerated in the coupling reaction, including bipyridyl (4d) and tripyridylamine (4g). Typical coupling reaction times ranged from 18 to $48 \mathrm{~h}$. Efforts to incorporate a $\mathrm{Cu}(\mathrm{I})$ cocatalyst, such as $\mathrm{CuI}$, resulted in only trace amounts of product being formed. Nevertheless, the syn N-donor ligands 5a-g were obtained in 79-99\% yield under the optimized conditions.

Cross-coupling of $\mathbf{2}$ with two other heteroaryls was also examined. To provide a point of comparison to the original synthesis of $\mathrm{Et}_{2} \mathrm{BCQEB}$, the reaction of $\mathbf{2}$ with quinoline triflate $\mathbf{6}^{7}$ (entry 8 ) was performed. Coupling of $\mathbf{2}$ with $\mathbf{6}$ gave a mixture of mono- and dicoupled product under the same conditions used to assemble 5a-g but proceeded smoothly with $10 \mathrm{~mol}$ $\%$ of $\mathrm{PdCl}_{2}\left(\mathrm{PPh}_{3}\right)_{2}$ and $50 \mathrm{~mol} \%$ of $\mathrm{CuI}$ in a mixture of $\mathrm{Et}_{3} \mathrm{~N}$ and THF at $\mathrm{rt}$, providing the diquinoline product $\mathbf{5 h}$ in $67 \%$ yield. To access an imidazole derviative, reaction of $\mathbf{2}$ with 4iodo-3-methylimidazole ${ }^{15}$ (7, entry 9) was conducted with $10 \mathrm{~mol} \%$ of $\mathrm{PdCl}_{2}\left(\mathrm{PPh}_{3}\right)_{2}$ in piperidine at $65{ }^{\circ} \mathrm{C}$, affording the diimidazole $5 \mathbf{i}$ in $65 \%$ yield.

By using a more convergent synthetic strategy and switching from quinoline to pyridine $\mathrm{N}$ donor substituents, the overall efficiency of preparing the syn $\mathrm{N}$-donor ligands described in this account was considerably enhanced. The pyridine-based ligands $\mathbf{5 a}-\mathbf{g}$ were obtained in four steps and 40-50\% overall yield from 1,2,4,5-tetrabromobenzene, a substantial improvement over the efficiency of assembling $\mathrm{Et}_{2} \mathrm{BCQEB}$ ( $2 \%$ over seven steps). The higher convergence of this strategy also allowed the quinoline congener $\mathbf{5 h}$ to be accessed in two fewer steps and nearly five times ( $9 \%$ overall yield from anthranilic acid ${ }^{16}$ ) more efficiently 
than $\mathrm{Et}_{2} \mathrm{BCQEB}$. Access to the imidazole derviative $\mathbf{5 i}$ was also possible by using this strategy, proceeding in four steps and $33 \%$ overall yield.

In conclusion, an efficient synthesis of a new family of syn $\mathrm{N}$-donor ligands is described. With ready access to these ligands, their iron coordination chemistry can now be investigated.

Preliminary work indicates that the pyridine-based ligands support dimetallic structures. The mixed iron-sodium complex of ligand $\mathbf{5 a},\left[\mathrm{FeNa}(\mathbf{5 a})\left(\mu-\mathrm{O}_{2} \mathrm{CTrp}\right)_{3}\right]$ (Figure 3), was recently isolated and characterized by X-ray crystallography. ${ }^{17}$ Replacement of sodium by iron in this complex was possible, providing a rare opportunity to study metal substitution chemistry in a dinuclear structure. Further experiments involving the iron coordination chemistry of these ligands, as well as the synthesis of other derviatives by the strategy disclosed herein, are ongoing.

\section{Acknowledgements}

This work was supported by Grant No. GM32134 from the National Institute of General Medicine Sciences. J.J.K. thanks the National Institutes of Health for a postdoctoral fellowship (F32 GM069236-01), and A.J.M. thanks the MIT UROP program for funding.

\section{References}

1. Merkx M, Kopp DA, Sazinsky MH, Blazyk JL, Müller J, Lippard SJ. Angew Chem, Int Ed 2001;40:2782-2807.

2. Stubbe J, van der Donk WA. Chem Rev 1998;98:705-762. [PubMed: 11848913]

3. Fox BG, Lyle KS, Rogge CE. Acc Chem Res 2004;37:421-429. [PubMed: 15260504]

4. a Tshuva EY, Lippard SJ. Chem Rev 2004;104:987-1012. [PubMed: 14871147] b Tolman WB, Que L Jr. J Chem Soc, Dalton Trans 2002;5:653-660. c Du Bois J, Mizoguchi TJ, Lippard SJ. Coord Chem Rev 2000;200-202:443-485.

5. A di( $\mu$-oxo)diiron(IV) species similar to $Q$ was thought to be generated with the ligand BPMCN, which has an all-N-donor ligand set. A recent study reveals this compound to be mononuclear, however, illustrating the difficulty of the task. See: JensenMPCostasMHoRYNKaizerJMairata i PayerasAMünckEQueLJrRohdeJUStubnaAJ Am Chem Soc20051271051210525and ref. cited therein. [PubMed: 16045338]

6. Density functional theory (DFT) calculations implicate the oxygen atom trans to the two histidines in the di( $\mu$-oxo) intermediate $\mathrm{Q}$ to be the reactant that is inserted into the $\mathrm{C}-\mathrm{H}$ bond of methane. BaikMHGhermanBFFriesnerRALippardSJJ Am Chem Soc20021241460814615 [PubMed: 12465971]

7. Kuzelka J, Farrell JR, Lippard SJ. Inorg Chem 2003;42:8652-8662. [PubMed: 14686842]

8. For an example of this type of strategy, see: KawanoTKuwanaJShinomaruTDuCXUedaIChem Lett200112301231

9. ,3-Dibromotriptycene is available in one step and $62 \%$ yield from 1,2,4,5-tetrabromobenzene. See: HartHBashir-HashemiALuoJMeadorMATetrahedron 19864216411654

10. a Song JJ, Yee NK. J Org Chem 2001;66:605-608. [PubMed: 11429837] b Comins DL, Killpack MO. J Org Chem 1990;55:69-73. c Wang X, Rabbat P, O'Shea P, Tillyer R, Grabowski EJJ, Reider PJ. Tetrahedron Lett 2000;41:4335-4338. d Fang YQ, Hanan GS. Synlett 2003;6:852-854.

11. Substitution and palladium-catalyzed cross-coupling reactions occur selectively at the 2 position of 3 , due to that site's higher electrophilictiy, whereas lithium halogen exchange occurs selectively at the 5 position. For early examples, see: (a)

TestaferriLTieccoMTingoliMBartoliDMassoliATetrahedron19854113731384 b Tilley JW, Zawoiski S. J Org Chem 1988;53:386-390. c Bolm C, Ewald M, Felder M, Schlingloff G. Chem Ber 1992;125:1169-1190.

12. For a related example with 6,6'-dibromo-2,2'-bipyridyl, see: ZhuYZLiZPMaJATangFYKangLZhouQLChanASTetrahedron: Asymmetry200213161165For a palladium-catalyzed example, see: JorgensenMLeeSLiuXWolkowskiJPHartwigJFJ Am Chem Soc20021241255712565 [PubMed: 12381200] 
13. This is a major improvement from the known route to PACs of this type; 5-bromopyridine acetic acid methyl ester is available in four steps and $<20 \%$ overall yield from 3-bromopyridine.

JonesGPitmanMALuntELythgoeDJAbarcaBBallesterosRElmasnaouyMTetrahedron 19975382578 268

14. Policar C, Lambert F, Cesario M, Morgenstern-Badarau I. Eur J Inorg Chem 1999:2201-2207.

15. Holden KG, Mattson MN, Cha KH, Rapoport H. J Org Chem 2002;67:5913-5918. [PubMed: 12182622]

16. The lower overall yield in the preparation of $6 \mathrm{f}$ is largely due to inefficient steps in the preparation of the quinoline triflate 7 , which is available in four steps and $13 \%$ yield from anthranilic acid. ${ }^{7}$

17. Kodanko, J. J.; Xu, D.; Lippard, S. J. Submitted for publication. 


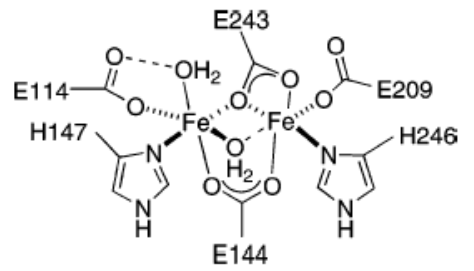

Figure 1.

Representation of methane monooxygenase hydroxylase (MMOH) active site in its reduced, diiron(II) state. 


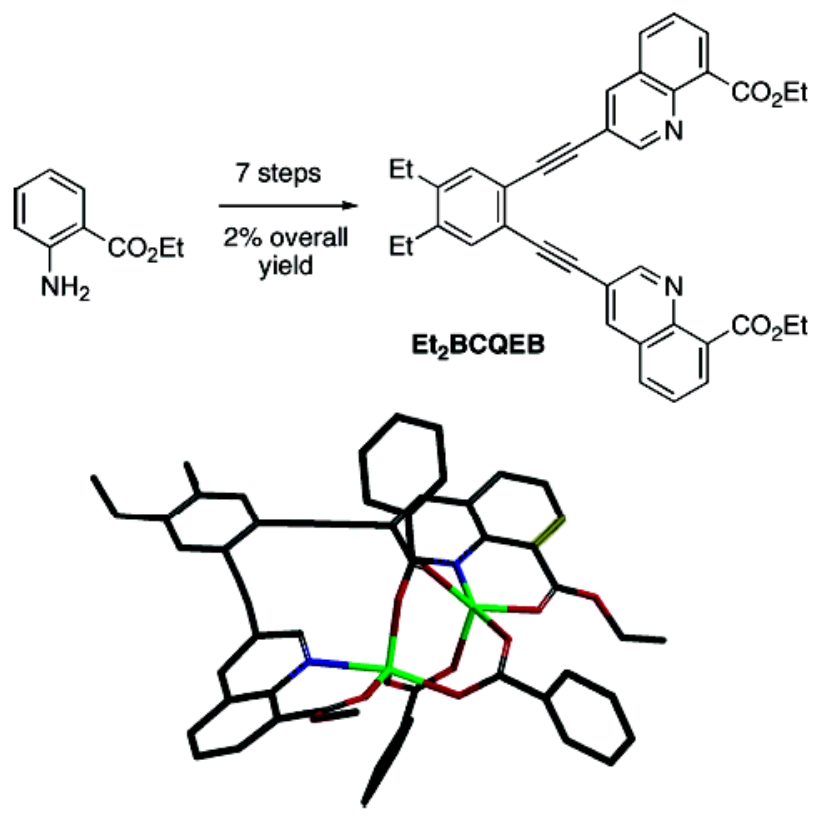

Figure 2.

Synthetic route to $\mathrm{Et}_{2} \mathrm{BCQEB}$ and structure of $\left.\left[\mathrm{Fe}_{2}\left(\mathrm{Et}_{2}-\mathrm{BCQEB}\right)\left(\mu-\mathrm{O}_{2} \mathrm{CAr}{ }^{\mathrm{Tol}}\right)_{3}\right](\mathrm{OTf})\right]$. The triflate counterion and tolyl groups of $\mathrm{O}_{2} \mathrm{CAr}^{\mathrm{Tol}}$ are omitted for clarity. 


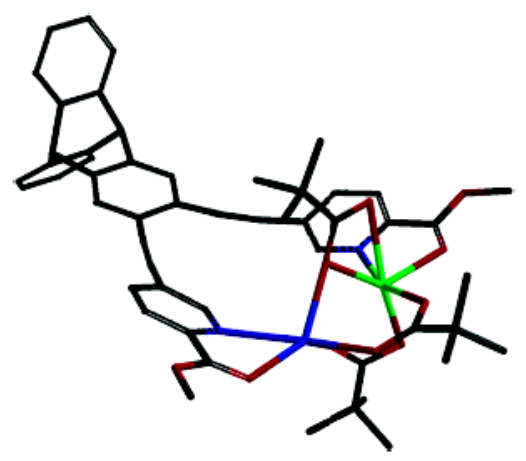

Figure 3.

Synthesis and structure of $\left[\mathrm{FeNa}(\mathbf{5 a})\left(\mu-\mathrm{O}_{2} \mathrm{CTrp}\right) .{ }^{17}\right.$ The iron atom is shown in blue. The triptycene carboxylates ( $\operatorname{Trp}=9$-triptycenyl) are abbreviated as pivolate groups for clarity. 

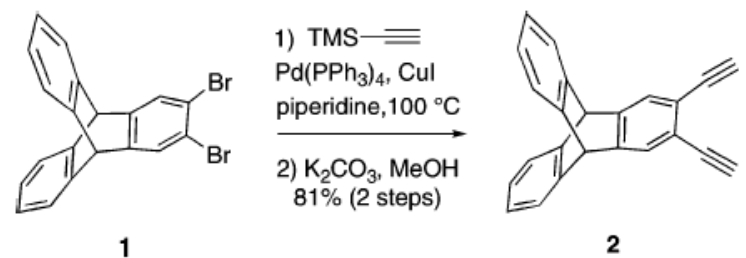

Scheme 1 .

Synthesis of 2,3-Diethynyltriptycene (2) 


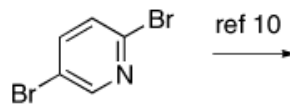

3

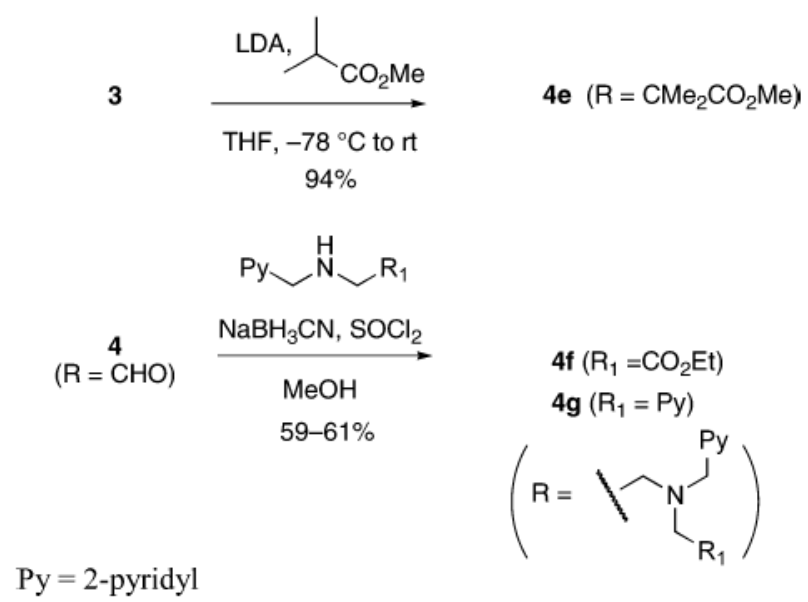

Scheme 2 .

Heteroaryl Coupling Partners from 2,5-Dibromopyridine 
Synthesis of Syn N-Donor Ligands 5a-i

\section{Table 1}

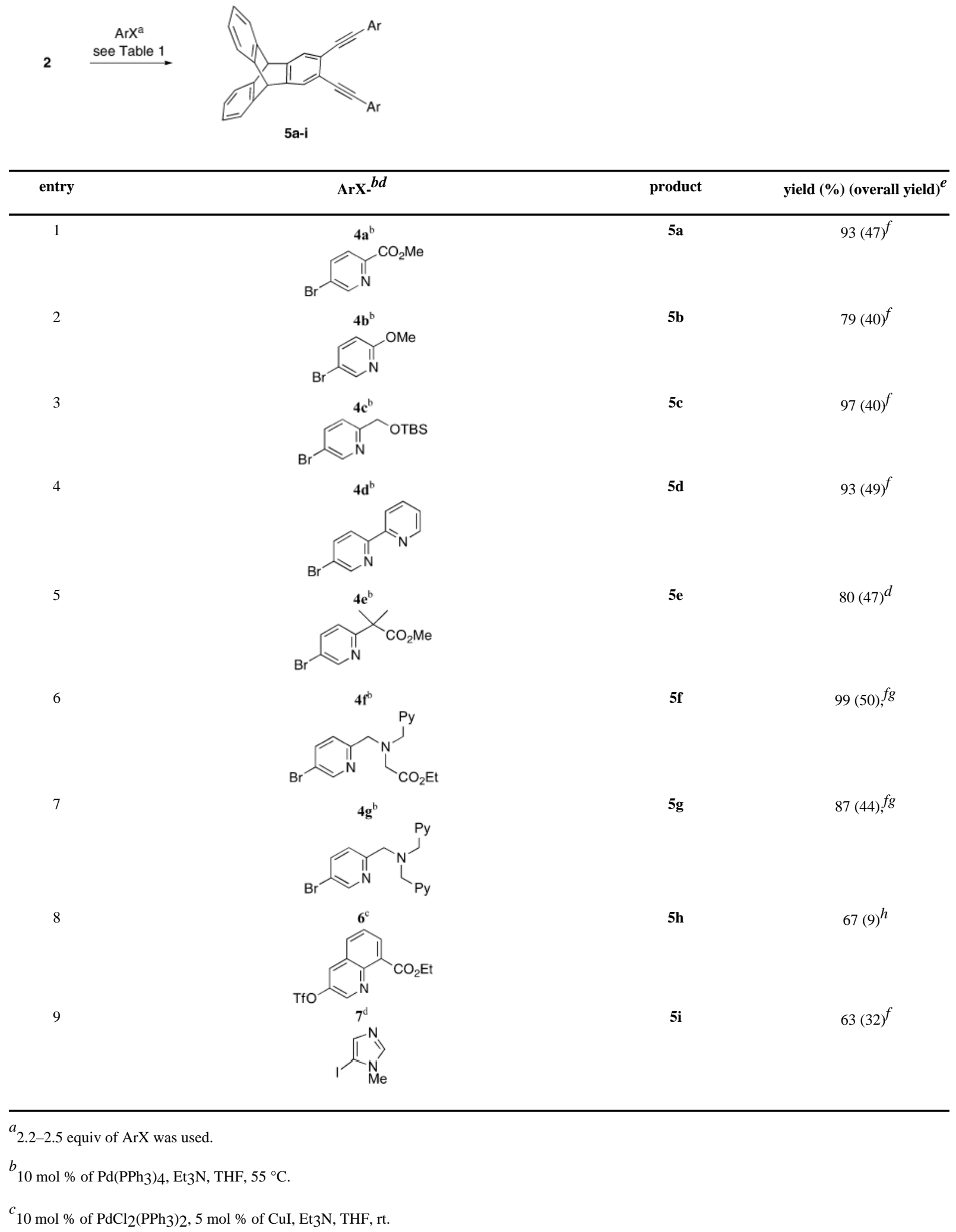

Org Lett. Author manuscript; available in PMC 2006 August 23. 
$d_{10 \mathrm{~mol}} \%$ of $\mathrm{PdCl}_{2}\left(\mathrm{PPh}_{3}\right) 2$, piperidine, $65^{\circ} \mathrm{C}$.

${ }^{e}$ The overall yield is calculated for the longest linear sequence from commercially available materials.

$f_{\text {Overall yield from 1,2,4,5-tetrabromobenzene. }}$

$g$ The yield was measured by ${ }^{1} \mathrm{H}$ NMR spectroscopy using an internal standard.

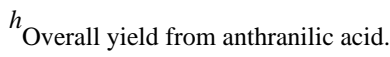

